\title{
Study on the Influence of Strategic Network Structure on Enterprise Management Innovation Behavior
}

\author{
Xuesong Li \\ College of Civil Engineering and Architecture, Wenzhou University, Wenzhou 325035, China \\ paperiset@163.com
}

Keywords: Strategic network, network Strategic resource, enterprise management innovation behavior.

\begin{abstract}
Based on a great amount of literature, the author found that the two research fields ignored each other, which leading to enterprise management innovation behavior can't be accurately known. The paper is trying to put the two aspects combining through constricting the model of the influence mechanism and the path of strategic networks affecting enterprise management innovation behavior in the perspective of social network. At the same time, we argue that the enterprise absorption ability also affect management innovation behavior. For this, the absorption ability is introduced into above model.
\end{abstract}

\section{Introduction}

The significance of strategic network for enterprise management innovation behavior has been concerned by many scholars in different research fields. But so far, we can't answer the following questions: how strategic network exert impact on enterprise management innovation behavior? What are the influence mechanism and the influence path of strategic network? We think these questions are the most essential problems for strategic network. Only to answer these questions, we can understand network management and network management ability profoundly and comprehensively [1].

The globalization of economy and the development of Strategic economy bring dramatic change to the innovation pattern of companies. This research introduces the concept of Strategic-based dynamic capabilities as the intermediate .variable, aiming to explore the influence mechanism of Strategic network towards innovation performance [2]. Applying 244 companies from Chinese coastal area as the sample, it establishes the influence mechanism framework from Strategic network to dynamic capabilities and finally to innovation performance and then provides empirical evidence for it.

In the field of strategic management scholars still can't give a clear answer on the mechanism and path of strategic network impacting on enterprise management innovation behavior. Secondly, the routing process of strategic network affect enterprise behavior and management innovation behavior is not clear. Along with the globalization competition intensifying and arrival of the era of network economy, enterprises' innovation mode has become network mode instead of the simple linear mode, which requires enterprises from the closed innovation to the open innovation. Enterprises' strategic cooperation mode also has gradually transformed into network cooperation modes; network becomes the important characteristics of the contemporary enterprise innovation. How to cultivate and develop effective innovation network is very meaningful for the enterprises break through the barrier that their innovation resources is limited and improve the ability of independent innovation [3]. Strategic network is the foundation of enterprise innovation, and innovation is increasingly becoming a main factor of enterprises improving their competitiveness, so in the strategic network, how to improve the enterprise's innovation performance is the important issues that scholars focus on. While in the field of sociology, especially with the development of the social capital theory, scholars provide the supplementary for above two research aspects. Based on a great amount of literature, the author found that the two research fields ignored each other, which leading to enterprise management innovation behavior can't be accurately known. The paper is trying to put the two aspects combining through 
constricting the model of the influence mechanism and the path of strategic networks affecting enterprise management innovation behavior in the perspective of social network. At the same time, we argue that the enterprise absorption ability also affect management innovation behavior. For this, the absorption ability is introduced into above model.

\section{Conceptual model and research hypothesis}

First of all, this papers definite the key concepts for meeting the need of follow-up studies. Secondly, the foreign and domestic literature research were discussed and evaluated in order to offer the thought foundation for the model. Based on the above two steps, the conceptual model was constructed and the corresponding research hypothesis ware put forward. Thirdly, the final questionnaire was designed through the test of the reliability and validity. Then, a mount of data ware collected through field study based on above questionnaire [4]. Toughly, the SEM of this paper was constructed through using the software of AMOS, and then was made empirical test.

The research purposes to answer four questions. First, restructure the concept of dynamic capabilities from the perspective of enterprise Strategic and find out its path of evolving; Second, analyze the impact of Strategic network over anemic capabilities and prove the difference in different stages during the evolvement of dynamic capabilities; Third, demonstrate the different impacts of various dimensions of dynamic capabilities over technological innovation and management innovation;

Fourth, elaborate the influence mechanism framework of Strategic network to innovation performance and explore the 'fit' among network feature, dynamic capabilities and innovation pattern.

Data in this research are collected through interviews and questionnaires from 244 companies and are processed by SPSS16.0 and AMOS7.0. Besides social surveys, this research also employs social network method to measure network structure and relation.

\section{Research method design}

Strategic networks affect enterprise management innovation behavior through influencing the access of network Strategic resources. Obviously, network Strategic resource plays a intermediate role in the process of strategic network affecting enterprise management innovation behavior, while networks impact on management innovation behavior indirectly. And network Strategic resource positive correlate with enterprise management innovation behavior. Identify external Strategic quickly and integrate it with existing Strategic so as to realize new resource combination [5].

Strategic in the ever-changing environment, dynamic capabilities can be divided into three dimensions, namely searching and identifying, selecting and evaluating, transforming and integrating. They are sequence-dependent and evolve in the spiral of Strategic creation. The success of former stage is prerequisite of the success of the following stage, (Eq. (1)). Sketch map of network structure is shown in Fig. 1.

$$
\mathrm{T}=\frac{\chi 2 \text { (first-order) }}{\chi 2 \text { (first-order) }}=84 / 86=97.7 \%
$$




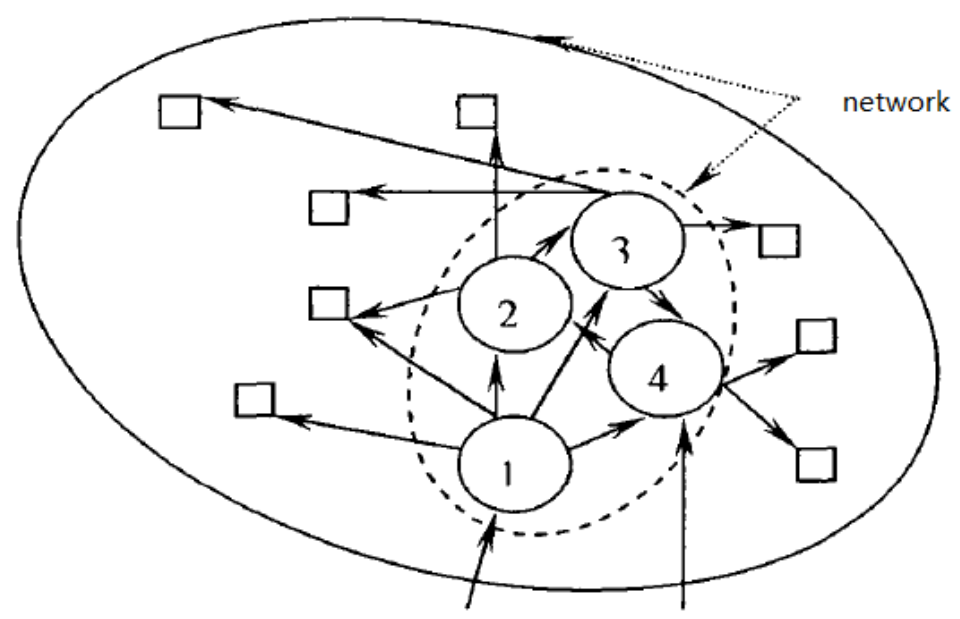

Fig. 1 Sketch map of network structure

Unfortunately, despite a wide concern for the entrepreneurs' social network in China and the emerging research and study for the network success hypothesis theory, the domestic scholars have outlined the characteristics of the entrepreneurs' social network and the outputted competitiveness brought by these characteristics; but these researches rarely focus on the empirical study about the mechanism and role of entrepreneurs' social network influences on technological innovation performance, also there are still some differences on the research regarding the actual effect of entrepreneurs' social network. [6] (Eq. (2))

$$
\mathrm{T}=\frac{\left.\chi^{2} \text { (first-order }\right)}{\chi^{2}(\text { second }- \text { order })}=94.98 \%
$$

Network fosters dynamic capabilities and various network features have different impact on various dimensions of dynamic capabilities. Is the key element to increase searching and identifying as well as transforming and integrating, whose influence is stronger than network size and network heterogeneity. Network size is positive related to searching and identifying while has no significant direct influence on. Transform and integrate. Network heterogeneity has no significant direct influence on searching and identifying while is - negatively-related 0 to transform -WD integrates [7]. Strong ties prompts attain capabilities significantly. To be specific, high interaction frequency with first-class network members is positively related to transform and identify. High interaction frequency with second-class network members is positively related to searching and identifying. However, both influences are weaker than that of relation quality. Or put it in other words, the intimacy and higher level of trust reciprocity with network members is more decisive in that it can promote both searching and identifying as well as transform and integrate. Fitting results of network density measurement model is shown in Table 1.

Table 1 Fitting results of network density measurement model

\begin{tabular}{|c|c|c|c|c|c|c|}
\hline & & $\begin{array}{l}\text { Non standardized } \\
\text { coefficient }\end{array}$ & S.E. & C.R. & $\mathrm{P}$ & $\begin{array}{l}\text { Standardized } \\
\text { coefficient }\end{array}$ \\
\hline a1 & $\begin{array}{c}<---n e t w o r k \\
\text { density }\end{array}$ & 1.000 & & & & .675 \\
\hline a2 & $\begin{array}{l}<--- \text {-network } \\
\text { density }\end{array}$ & 1.164 & 0.103 & 11.299 & $* * *$ & .811 \\
\hline a3 & $\begin{array}{c}<---n e t w o r k \\
\text { density }\end{array}$ & 1.047 & 0.101 & 10.411 & $* * *$ & .722 \\
\hline \multirow[t]{5}{*}{ a4 } & $\begin{array}{c}<---n e t w o r k \\
\text { density }\end{array}$ & 1.197 & 0.106 & 11.275 & $* * *$ & .808 \\
\hline & $x^{2}$ & 5.404 & & GFI & & 990 \\
\hline & & & & CFI & & .992 \\
\hline & dd & 2 & & TLI & & .977 \\
\hline & $x^{2} / d f$ & 2.702 & & RMSEA & & .077 \\
\hline
\end{tabular}


There exist significant differences in terms of influential elements and evolving path of technological innovation and managerial innovation. In the first place, they have different demands on external Strategic. Managerial innovation highlights the combination of external Strategic and existing Strategic while technological innovation relies more on heterogeneous external Strategic. The integration of internal and external Strategic has no significant impact on technological innovation. Searching and indenting is positively related to both technological and management innovation, although its impact on technological innovation is stronger than on management innovation. Indeed; searching and identifying is the key factor to promote technological innovation whereas transforming and integrating is the key to. In the second place, management innovation can promote technological innovation, while technological innovation does not necessarily leads to management innovation. The impact of management innovation on technological innovation is second to that of searching and identifying. Ignoring management innovation will lower the overall innovation level of a company. Technological innovation has no significant direct impact on management innovation. (Eq. (3))

$$
\left\{\begin{array}{l}
\frac{\mathrm{d} \chi_{1}}{\mathrm{dt}}=\mathrm{r}_{1} \chi_{1}\left(1-\frac{\chi_{1}}{\mathrm{C}_{1}}+\sigma_{1} \frac{\chi_{2}}{\mathrm{C}_{2}}\right) \\
\frac{\mathrm{d} \chi_{2}}{\mathrm{dt}}=\mathrm{r}_{2} \chi_{2}\left(1-\frac{\chi_{1}}{\mathrm{C}_{2}}+\sigma_{2} \frac{\chi_{1}}{\mathrm{C} 1}\right)
\end{array}\right.
$$

Strategic network impacts on innovation performance via the intermediary fanatic capabilities. There is dynamic fit mechanism among network features, dyanamic capabilities and innovation pattern. Technological innovation highlights searching and identifying external Strategic. And network centrality, network size, relation quaiityand the interaction frequency with second-class network members promotes technological innovation via their positive impact on searching and identifying. Network size and the interaction frequency with second-class network members promote management innovation via their positive impact on searching and identifying. Interaction frequency with first-class network members promotes management innovation via its positive impact on transforming and integrating. Network heterogeneity deters management innovation via its negative impact on transforming and integrating. Network centrality and the relation quality promote management innovation via their positive impact on searching and identifying. Fitting results of potential absorptive capacity measurement model is shown in Table 2.

Table 2 Fitting results of potential absorptive capacity measurement model

\begin{tabular}{|c|c|c|c|c|c|c|c|}
\hline & & & $\begin{array}{c}\text { Non standardized } \\
\text { coefficient }\end{array}$ & S.E. & C.R. & $\mathrm{P}$ & $\begin{array}{c}\text { Standardized } \\
\text { coefficient }\end{array}$ \\
\hline a8 & $<---$ & $\begin{array}{l}\text { PACA } \\
\text { P }\end{array}$ & 1.000 & & & & .631 \\
\hline a9 & $<---$ & $\begin{array}{l}\text { PACA } \\
\quad \mathrm{P}\end{array}$ & 1.054 & .114 & 9.218 & $* * *$ & .687 \\
\hline a10 & $<---$ & $\begin{array}{c}\text { PACA } \\
\text { P }\end{array}$ & 1.179 & .125 & 9.413 & $* * *$ & .708 \\
\hline a11 & $<---$ & $\begin{array}{l}\text { PACA } \\
\text { P }\end{array}$ & 0.986 & .113 & 8.709 & $* * *$ & .636 \\
\hline a12 & $<--$ & $\begin{array}{c}\text { PACA } \\
\text { P }\end{array}$ & 1.003 & .111 & 9.057 & $* * *$ & .671 \\
\hline \multirow[t]{4}{*}{ a13 } & $<---$ & $\begin{array}{c}\text { PACA } \\
\text { P }\end{array}$ & 1.087 & .118 & 9.194 & $* * *$ & .685 \\
\hline & \multicolumn{2}{|c|}{$x^{2}$} & 8.974 & & GFI & & .990 \\
\hline & \multicolumn{2}{|c|}{$\mathrm{df}$} & 9.000 & & CFI & & 1.000 \\
\hline & \multicolumn{2}{|c|}{$\mathrm{x}^{2} / \mathrm{df}$} & 0.997 & & $\begin{array}{c}\text { TLI } \\
\text { RMSEA }\end{array}$ & & $\begin{array}{c}1.000 \\
.000\end{array}$ \\
\hline
\end{tabular}




\section{Empirical test of structural equation model}

Based on the empirical research method, and reviewing numerous domestic and international theory and literature about strategic network structure, organization learning and innovation performance, the paper takes that strategic network structure influences on the innovation performance as the breakthrough point, aims to further explore the intermediary role of the organizational learning between the strategic network structure and the innovation performance. In order to validate the hypothesis theory proposed by this study, the paper chooses 265 Chinese enterprises as the main research object. Through collect data by the questionnaire survey whose respondent is technical directors and middle and senior manager, applying SPSS17.0 and AMOS7.0 into reliability and validity analysis, multiple regression analysis, and constructs structural equation model of correlation variable's relationship, the paper further explores structure Influence relationships among strategy network structure, organization learning and innovation performance. In theory, this study makes the action mechanism of strategy network structure, organizational learning innovation performance clear, and at the same time enriches the related theory about strategic network, enterprise innovation and so on. The first sub-study on the basis of exploratory case studies of three manufacturing companies is to explore the mechanism that enterprises integrate external and internal resource, and transform resources into technological innovation capabilities. The research points out that the key to industrial transformation and upgrading is leveraging, innovation capability, which is also the basis of structural adjustment. Fitting result is shown in Table 3.

Table 3 Fitting result

\begin{tabular}{cccc}
\hline Estimate & S.E. & C.R. & $\mathrm{P}$ \\
\hline 1.000 & & & \\
.938 & .090 & 10.409 & $* * *$ \\
.531 & .062 & 8.538 & $* * *$ \\
1.000 & & & \\
.789 & .063 & 12.498 & $* * *$ \\
1.054 & .065 & 16.115 & $* * *$ \\
1.000 & & & \\
1.050 & .081 & 12.951 & $* * *$ \\
1.067 & 0.08 & 13.363 & $* * *$ \\
1.000 & & & \\
1.467 & .154 & 9.539 & $* * *$ \\
1.196 & .128 & 9.374 & $* * *$ \\
\hline
\end{tabular}

Innovation network reflects the nature of innovation and synergy which can utilize the scattered innovation resources effectively. And six initial assumptions are proposed. Insights from the case studies provide theoretical ideas from practice for the study that followed in the next sections. The second sub-study proposes assumptions on the basis of the first sub-study, and makes in-depth analysis under the related theoretical discussion. By the I zoomorphism of reconstruction, this sub-study treats enterprise as a structure composed of different elements and departments, and builds the overall framework of enterprise's internal and external innovation network synergy and innovation capability mechanism. By questionnaire survey of 278 enterprises in Zhejiang and Shandong Province, this sub-study utilizes high order factor model of structural equation model to analyze the internal and external innovation network synergy in three steps: (1) Analyzing each dimension's influence of internal and external innovation networks on different innovation capability (exploration and exploitation); (2) Analyzing second-order constructs' significant correlation (namely interaction) of internal and external innovation networks; (3) Constructing second-order factor as a general entity which represents the complementary characteristic of different dimensions. By introduces environment dynamic variable, it studies the stern or direction of influence of environment toward the relationship between capability and performance. The third sub-study is based on the previous two studies and uses system dynamics (SD) method for analyzing the internal 
and external innovation networks synergy and the dynamic evolution characteristics of innovation capability. It first establishes a second-order model on the basis of structural equation, in order to studies the dynamic influence of enterprise's internal and external innovation network synergy toward innovation capability. Then, under case studies, it establishes first-order system dynamic model to explore the dynamic evolution relationship between enterprise's internal innovation element synergy and innovation capability in the context network environment. Finally, it summarizes the dynamic law of element synergy innovation capability evolution in innovation network. Regression coefficients between items and variables are shown in Table 4.

Table 4 Regression coefficients between items and variables

\begin{tabular}{ccccc}
\hline Estimate & S.E. & C.R. & $\mathrm{P}$ & Standardized \\
\hline 1.000 & & & & .785 \\
1.075 & .070 & 15.351 & $* * *$ & .892 \\
0.957 & .066 & 14.511 & $* * *$ & .829 \\
1.000 & & & & .596 \\
1.525 & .161 & 9.459 & $* * *$ & .760 \\
1.549 & .158 & 9.803 & $* * *$ & .810 \\
1.463 & .167 & 8.767 & $* * *$ & .676 \\
1.285 & .142 & 9.038 & $* * *$ & .708 \\
1.000 & & & & .784 \\
1.081 & .982 & 11.739 & $* * *$ & .712 \\
0.948 & .082 & 11.587 & $* * *$ & .704 \\
1.112 & .082 & 13.564 & $* * *$ & .821 \\
1.000 & & & & .766 \\
1.069 & .095 & 11.254 & $* * *$ & .717 \\
1.236 & .099 & 12.533 & $* * *$ & .833 \\
\hline
\end{tabular}

Research focuses on the dynamic evolution of enterprises' innovation capability in network and is carried out from two research level-the synergy of enterprise' internal network and external network, and the synergy of enterprise's internal elements. The first research level refers to the synergy between internal and external enterprise, interaction. it verifies that the internal network and external network exists complementary on the basis of interaction promotes the development of exploration innovation capability and exploitation innovation capability simultaneously, and promotes the construction of ambidextrous organization in a longer duration. The second research level refers to the synergy of enterprise's internal elements and mufti-dimensional elements' combination promotes the capability transformation from non-cure capability to core capability. The establishment of enterprise's original capability needs support and guidance from synergy of strategy and culture.

\section{Summary}

Enterprise absorptive capacity plays an important role in the process of strategic network affecting network Strategic resource and enterprise management innovation behavior. The empirical conclusion is that the potential absorptive capacity positive correlates with network Strategic resources, while the realistic absorptive capacity positive correlates with network Strategic resources and enterprise management innovation behavior.

\section{References}

[1] Wang Y L. The Strategic Network Structure of Overseas Subsidiaries and lts Differentiation:A View from the Theory of Social Embeddedness. Economic Survey, 2008.

[2] Bing-Ying L I. Study on Strategic Network Structure and Information Application Innovation. Information Science, 2007. 
[3] Rosenkranz S, Weitzel U. Network structure and strategic investments: An experimental analysis. Ssrn Electronic Journal, 2008, 43(8-24):743-760.

[4] Vanhaverbeke W P M, Gilsing V A, Beerkens B E, et al. Benefits and risks of strategic collaboration : the differential role of a firm's network structure in the creation of core and non-core technologies. Pucsp Br, 2009:456-478.

[5] Liu H, Zang N L. The Influence of Technological Innovation Management Behavior to the Innovation Achievements Infcuence By Construction Enterprise as an Example. Technoeconomics \& Management Research, 2011.

[6] Zhao Z H, Ju X F. Game analysis of enterprise innovation behavior based on technology spillovers. Advances in Information Sciences \& Service Sciences, 2013:1640-1645.

[7] Gao S. Study on the Relationship of Leader-Member Exchange and Employees' Innovation Behavior in High-tech Enterprises. Technology \& Innovation Management, 2015. 